Chapter 4

\title{
Marine Natural Products for Protein Misfolding Modulation
}

\author{
James C. Giffin and Kathryn Vanya Ewart \\ Additional information is available at the end of the chapter \\ http://dx.doi.org/10.5772/54585
}

\section{Introduction}

Proteins are linear covalent chains of amino acids. In most proteins, the chain winds in a specific way to adopt a set fold, or "conformation", that is stable and that allows it to function. A number of proteins remain unfolded in their native state and these are referred to as intrinsically disordered proteins. These unfolded proteins remain soluble and functional and some exhibit specific ligand binding capability, which can cause them to adopt an induced fold. In contrast to these two functional situations of natively folded and disordered proteins, proteins that are normally folded or disordered can misfold, that is, to fold incorrectly.

Proteins may misfold as a result of enzymatic cleavage, post-translational modification, mutation, overabundance or structural destabilization due to alteration in the tissue environment. Accumulation of misfolded proteins can occur more readily when proteostasis mechanisms that foster correct folding of proteins, such as the chaperone system, and that clear the cell of misfolded proteins, such as the ubiquitin-proteasome system, are compromised [1]. A subset of human proteins appears to have an unusual tendency to misfold and this is recognized as a central event in a number of human diseases (reviewed by [2]). Improper folding often leads to problems because the misfolded protein cannot perform its normal role (loss of essential function) and because it assembles into oligomeric forms or larger aggregates that are toxic to the cell (gain of harmful function) [3]. The most recognized misfolded conformation is a stacking of $\beta$-sheets forming a crossed- $\beta$ secondary structure that assembles into a linear multimeric fiber called amyloid (reviewed in [2]).

Several neurodegenerative diseases share protein misfolding as an underlying cause $[4,5]$. These diseases can be classified based upon the proteins affected [3] while sharing a common mechanism of emergence. Protein misfolding in neurodegenerative diseases has been the focus of many reviews; excellent examples are in [5-9]. Therefore, a comprehensive re- 
view will not be undertaken here. The canonical neurodegenerative diseases are Alzheimer's disease (AD), Parkinson's disease (PD), Huntington's disease, amyotrophic lateral sclerosis and the prion diseases. Although each involves distinct proteins, misfolding has a common role. Huntington's disease is caused by an excessive number of sequential glutamines near the $\mathrm{N}$ terminus of the protein huntingtin. An expansion of the natural glutamine stretch exceeding approximately 33 residues results in Huntington's symptoms and the age of onset of the disease declines with increasing residue number [10-12]. A likely reason for this is the increased propensity for aggregation with increasing polyglutamine length [13]. Amyotrophic lateral sclerosis is a disease associated with the death of the upper and lower motor neurons in the spinal cord, brain stem and motor cortex. The affected neurons accumulate aggregate protein inclusions that may be causing the cells to die. Mutations in genes encoding superoxide dismutase-1, TAR DNA binding protein 43 and fused in sarcoma/ translation in liposarcoma (FUS/TLS) are implicated in ALS (reviewed in [14]). Prion diseases display several interesting commonalities with these other neurodegenerative diseases. Prion diseases emerge from misfolded prion protein, which serves as a template for subsequent misfolding of native prion protein with ensuing aggregation and neuron loss. The propagation of pathogenic misfolding from one protein molecule to its healthy neighbours by templating was long considered to be unique to prions; however, recent studies have suggested that molecular templating of misfolded proteins occurs with other neurodegenerative diseases as well. Furthermore, templating is inferred by observation of their spatial spread from select foci in the brain $[5,15,16]$. It is notable that prion diseases, which are infectious, may occur in animals or humans of all ages, whereas the apparently non-transmissible protein folding diseases occur mainly with ageing. This implies that a key step in all protein folding disease may be the initial establishment of a misfolded protein in a neuron, whether it is a misfolded protein taken in at any age by infection or misfolding that emerges in a susceptible endogenous protein due to faltering proteostasis with ageing. Therefore, the prevention of misfolding and/or the promotion of disaggregation and refolding of misfolded proteins in vivo appear to be the most direct means of dealing with all these diseases.

In this chapter, the focus is on $\mathrm{AD}$ and $\mathrm{PD}$, as these are the two most prevalent neurodegenerative diseases, and the proteins that misfold in these diseases are well studied. AD accounts for approximately two thirds of all cases of dementia [17]; it leads to cognitive deficits in reasoning, memory, abstraction and motor skills, with eventual death. It is characterized at the molecular level by extracellular aggregates of a short peptide called amyloid beta $(A \beta$, and also called beta amyloid), which can form oligomers and larger fibrils with amyloid structure and later emerging intracellular neurofibrillary tangles that are composed of hyperphosphorylated tau protein (reviewed in [18]). In this chapter, $A \beta$ normally refers to $\mathrm{A} \beta_{42}$, which is the 42-residue peptide and also appears to be most toxic form. There is increasing evidence that the $\mathrm{A} \beta$ oligomers have a key and likely causative role in AD. Most compelling are studies showing mutations in the regulatory region or encoded protein sequence in amyloid precursor gene in families predisposed to AD [19-21]. In contrast to AD, PD has been found to involve the misfolding of $\alpha$-synuclein $(\alpha S)$ into aggregates found in Lewy bodies and Lewy neurites. PD affects the substantia nigra, a region of the brain in- 
volved with reward, addiction and movement. Many of the onset symptoms of PD reflect this, and the diagnosis is based on resting tremor, slowness of movement, rigidity and postural instability [22]. These two proteins are unrelated in sequence and they have distinct structures in their native form, with $\mathrm{A} \beta$ a short mainly unstructured peptide and $\alpha \mathrm{S}$ a larger 140-residue protein that is post-translationally modified and that can exist in alternative conformations including a largely $\alpha$-helical form and a disordered state [23, 24]. In spite of these differences, both proteins misfold and aggregate, and the aggregates of each can be detected and measured using assays that will be discussed in the section below.

There is growing interest in the development of protein folding modulators that would offer to prevent or alleviate misfolding and to avoid the damage that occurs in neurodegenerative diseases. There has been progress along several avenues, but no magic bullet to date. Nonetheless, there remains substantial untapped diversity among natural products and notably in marine resources. With a focus on $\mathrm{A} \beta$ and $\alpha \mathrm{S}$, which are implicated in $\mathrm{AD}$ and PD, respectively, this chapter will examine natural agents that may prevent or ameliorate protein misfolding diseases, with particular attention to the potential of marine resources for possible discovery and development.

\section{Screening and evaluation for action on protein folding}

With the recognition that protein misfolding is a cause of several neurodegenerative diseases and a common mechanism of their progression, promising developments have begun to emerge (reviewed in the next section). These have relied upon the measurement of protein misfolding modulation as an early step in screening and evaluation of new active molecules or as a follow-up step in the evaluation of known and promising candidates because of their suspected effects on the diseases. Identification of a molecule as a folding modulator raises the possibility that it could address the cause of $\mathrm{AD}$ or $\mathrm{PD}$, rather than only addressing their symptoms, which makes products identified in this way potentially valuable in prevention as well as in amelioration of existing disease.

\subsection{In vitro analysis of protein misfolding modulation}

For both $\mathrm{A} \beta$ and $\alpha \mathrm{S}$, the transition from the native state to an amyloid conformation is not direct, but involves steps or stages. These may include unfolding, oligomerization and further aggregation into amyloid fibrils, with the possibility of off-pathway aggregation or reversal of these processes $[25,26]$. This is summarized in Fig. 1. Compounds may prevent misfolding and/or templating by inhibiting the unfolding of a natively folded protein, by promoting the folding of an unfolded form, by preventing amyloid formation or by diverting the protein toward an alternative aggregation pathway leading to a less harmful aggregate. A selection of assay approaches to misfolding evaluation will be compared here in terms of information value, throughput and versatility. 


\section{Native folded protein

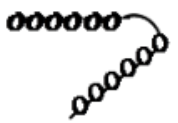

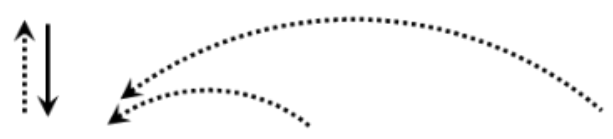

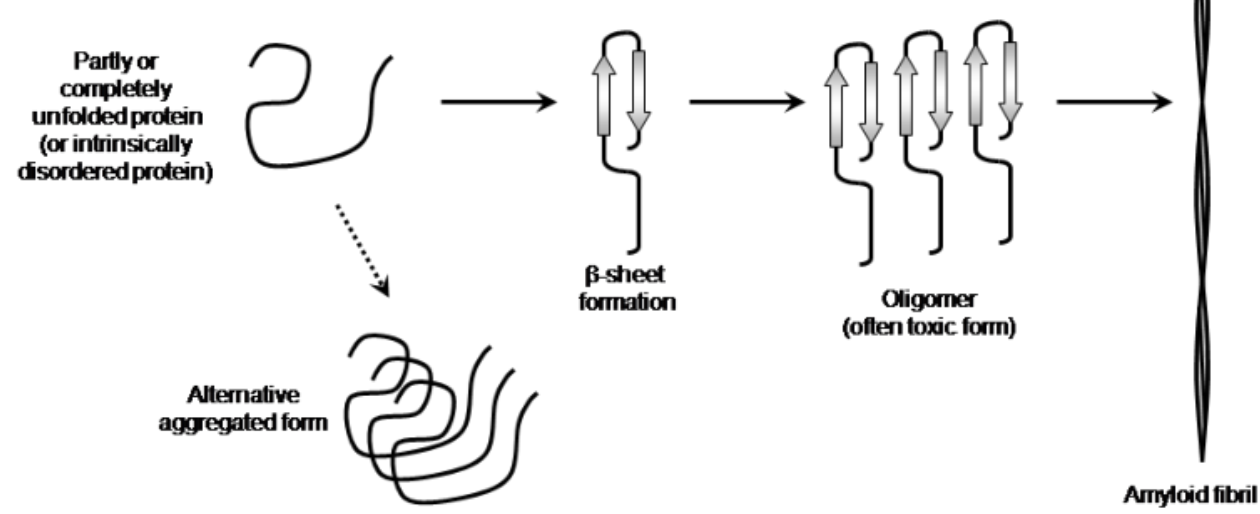

Figure 1. Overview of the general trajectory of protein misfolding with amyloid formation. Solid black arrows show pathway toward amyloid formation and stippled arrows show pathways of prevention or reversal of amyloid and related oligomers. This is an original diagram based upon information in reviews [2, 23].

\subsubsection{Protein unfolding}

For the discovery and development of novel agents against diseases such as AD and PD, a fuller picture of the action of a compound can be obtained by investigating the distinct steps of unfolding, aggregation, misfolding and amyloid formation. Proteins may remain largely folded and still produce amyloid or similar aggregates, provided that a local aggregationprone sequence is exposed [27]. Nonetheless, for most proteins that readily form amyloid, it appears that that the loss of native folding is a required step [27]. Both $\mathrm{A} \beta$ and $\alpha \mathrm{S}$ appear to have some unfolded or disordered character, but with regions that can become helical under appropriate conditions [28-30]. Inducing or preserving this helical conformation is a rational approach to preventing amyloid formation [29, 31, 32].

Folded and unfolded proteins differ in several characteristics that can be easily measured and that would allow folding modulators to be detected and evaluated. Some of the most common methods are summarized here. For example, proteins absorb right and left-circularly polarized light differently; this circular dichroism (CD) can be measured over a series of wavelengths to give informative spectra. The CD spectra of unfolded and folded proteins differ and those of proteins with predominantly $\alpha$-helix and $\beta$-sheet secondary structure can be easily distinguished. In more detailed studies, the proportion of each major secondary 
structure in a protein can be calculated from the spectrum using software such as DICHROWEB [33]. Moreover, diagnostic features such as minima at wavelengths of 208 and $222 \mathrm{~nm}$ for $\alpha$-helical proteins can be monitored in order to quantify changes in fold in response to temperature, solution components or other factors. To date, CD has been used for smallscale studies on protein folding and protein-ligand interaction because throughput is limited to a single sample at a time. The recent development of a high-speed automated CD spectrometer (ACD, Applied Photophysics) may allow this approach to be employed more broadly in sample screening. An advantage of CD measurement is that it is an intrinsic property of a protein; thus, the spectra require no additive and the protein can be measured directly without accessory molecules or modifications. Another intrinsic feature of proteins that can be measured directly is fluorescence. Proteins with aromatic side chains fluoresce when exposed to UV light and this can undergo a shift in intensity or wavelength of intensity maximum with folding. Fluorescence can also be measured using new devices that allow miniaturized measurements in a parallel manner using a similar rapid-throughput approach (e.g. the Optim 1000, Avacta Innovative Analysis). Likewise, differential binding of dyes such as SYPRO Orange allow protein forms with different exposure of hydrophobic residues to solvent to be distinguished. In the case of SYPRO Orange, the dye is quenched when free in an aqueous solution, but it becomes unquenched when it interacts with the hydrophobic regions that are exposed upon protein unfolding and its fluorescence increases as a consequence. This measurement can be performed efficiently on large numbers of samples using devices designed for quantitative PCR [34]. Measurements by these approaches allow protein folding to be assessed and changes in fold and/or fold stability to be examined. An informative and frequently employed measure of fold stability is the melting temperature (Tm), as proteins with more stable folds normally melt at higher temperatures. The Tm can be determined by any of the above techniques. A compound that stabilizes the folded conformation of a protein would raise its Tm and this change can be easily quantified by the above approaches. A caveat with amyloid-forming proteins is that stabilized folding, as exhibited by a higher Tm, may not necessarily represent the native folding that is assumed to preclude amyloid formation. For this reason, CD is particularly valuable, as it also allows the secondary structure to be determined; a spectrum distinct from that of $\beta$-sheet would provide a reasonable indication that the stable form is native and unrelated to amyloid.

\subsubsection{Amyloid-like structure}

It was through dye binding that amyloid plaques were first discovered. Fibrous aggregates in tissues stained blue when treated with acid followed by iodine and the aggregates were termed amyloid because they were believed to be starch based upon the colour development (reviewed in [35]). Although it is a misnomer, the name amyloid has endured and several different dyes have become invaluable in the study of protein misfolding and amyloid formation in vitro.

Thioflavin T (ThT), a benzothiazole dye, and Congo red, a diazobenzidine dye, are both commonly used to quantify the amount of amyloid protein present in a solution. ThT was 
first described to have amyloid-binding ability over 50 years ago [36] and it has since been in widespread use in the study of amyloidosis and the search for possible binding molecules. Congo red has also been in use for amyloid detection and quantification for several decades since its first description in that role [37]. Both of these dyes undergo a red shift in their fluorescence emission when they interact with amyloid fibrils. They cannot be used to distinguish between amyloid fibrils and smaller aggregates; however, they allow quantitative analysis and they continue to find wide use in amyloid analysis. Thioflavin S is a mixture of components derived from ThT and it has no spectral shift in absorbance or emission, which makes it suitable only for imaging and not for quantitation in solution because of high background [35]. Derivatives of N-arylaminonaphtalene including ANS and bis-ANS bind primarily to early stage aggregation in amyloid formation [38, 39]. They have not been as widely used as ThT and Congo Red, but they may find greater use with the increasing focus on aggregation pathways (see section 3 below).

Recently, there has been interest in identifying newer binding fluorophores that allow oligomeric aggregates to be distinguished from fibrils. An example is the indole compound tryptophanol. It allows specific detection and quantitation of prefibrillar oligomeric $A \beta$ because its fluorescence is quenched only in the presence of that form of $A \beta$ with no similar quenching in the presence of $A \beta$ fibrils [40]. Another is the carbocyanine dye JC- 1 that distinguishes different aggregation states of $\alpha \mathrm{S}$ [41]. JC-1 allows real-time tracking of $\alpha \mathrm{S}$ aggregation, as different fluorescent signals are emitted for monomer and fibrillar binding and the ratio of the two signals allows for real-time visualization of $\alpha \mathrm{S}$ aggregation [41].

Another recent development is the elaboration of antibodies and related agents that recognize proteins exclusively in their amyloid conformation, allowing the amyloid portion of the protein in question to be detected and quantified. A monoclonal antibody raised against $\alpha S$ was shown to recognize the protein in its amyloid form and, although the anticipated use is mainly in vivo, it showed effective recognition in an in vitro ELISA format [42]. Novel antibodies, termed gammabodies, were engineered by grafting a series of peptide sequences from $A \beta$ into immunoglobulin variable regions [43]. These have found use in distinguishing oligomeric and amyloid forms of $\mathrm{A} \beta$ and this technology would be expected to be applicable to other aggregating proteins [43]. Since an amyloid-like structure is relevant to many diseases, a new capture and detection peptoid that behaves in a manner similar to an antibody offers unusual versatility. This peptoid, based upon a 6-amino acid stretch in the human $\operatorname{PrP}$ sequence, binds to the amyloid forms of $\mathrm{A} \beta, \alpha \mathrm{S}$, amylin and serpin [44].

Model proteins that undergo transition to an amyloid-like conformation may also offer alternatives for amyloid formation-related studies [45]. For example, the 37-residue natively $\alpha$-helical winter flounder (Pseudopleuronectes americanus) antifreeze protein wflAFP-6 (HPLC-6) adopts an amyloid-like structure during the freeze-thaw process [46, 47]. This may offer an interesting model system for the study of the conversion of a protein from its native form into amyloid fibrils $[47,48]$. The ability to generate rapid amyloid formation in wflAFP-6 using the freeze-thaw process would offer low background compared with $\mathrm{A} \beta$ assays and the consistent $\alpha$-helical nature of the native AFP may also allow initial unfolding steps to be more 
clearly evidenced than in proteins with less defined native structure. Nonetheless, a molecule found to be an amyloid-relevant folding modulator using AFP amyloid-like transition assays may be universal or nearly so, as in the case of the peptoid detection system described above, or it may be specific to the wflAFP-6 and have no effect on other amyloid-forming proteins. Therefore, in spite of its potential advantages, further study of the antifreeze protein model would be required before its adoption in an assay platform.

\subsubsection{Protein interaction during amyloid formation}

As the interaction between locally or entirely misfolded monomers appears critical to nonnative protein association, there is interest in identifying molecules that directly interfere with that process. Therefore, assays for binding competition or impedance have been developed. A convenient new microplate assay employs fluorescently labelled $A \beta$. Unlabelled $A \beta$ is coated onto the plate surface and then the labelled $A \beta$ is applied in solution and allowed to bind [49]. After unbound material is washed off, the fluorescence remaining can be used to determine the level of interaction of $A \beta$ [49]. Although the aggregation state of the $A \beta$ in solution or on the plate is not indicated, the assay indicates the interaction between in-solution and on-plate A $\beta$ that is inhibitable, which can be taken to represent either oligomer formation or assembly into larger fibrils. Thus, molecules that affect any part of this process can be readily identified. Nonetheless, with the aggregation state of the binding units unclear except where $A \beta$ fragments are used, this assay does not indicate which step(s) in assembly of the monomeroligomer-fibril are being affected.

$\mathrm{A} \beta$ oligomerization and fibril formation can be challenging to study in vitro using dyes and other methods because of spurious background oligomer formation and the difficulty in determining how much oligomer may already have formed in a starting sample [50]. For these reasons, assays that avoid these problems have garnered interest. In one example, a procedure was developed involving a semi-denaturing detergent-agarose gel electrophoresis followed by blotting and immunological detection with an appropriate antibody recognizing the protein in all its forms [51]. The method allows amyloid aggregate size distributions to be determined and the user can distinguish among the monomeric, oligomeric and large aggregated (likely fibril) forms. A drawback is that it involves a vacuum transfer of proteins from the gel to a PVDF membrane. A derived method employing capillary blotting to a nitrocellulose membrane, reminiscent of nucleic acid blotting, has made the assay more precise and scaleable for screening purposes [52]. These methods allow the association state of the starting material to be determined and the effect of any product to be evaluated in comparison. Another approach is to eliminate the possibility of aggregates in the starting solution. An example is an assay based upon the expression of the $A \beta$ sequence in tandem with green fluorescent protein (GFP) as a fusion within a bacterial cell [53]. Aggregation of A $\beta$ precludes GFP folding and so there is no fluorescence, whereas addition of a molecule impeding the aggregation of $A \beta$ results in GFP folding to its native structure with consequent fluorescence. A more directly quantifiable in vitro form of this assay was developed using the Venus yellow fluorescent protein (vYFP) instead of GFP, which allows denaturation and refolding under precisely controlled conditions to detect molecules that promote or inhibit aggregation [50]. 


\subsection{Cell- and organism-based analyses}

Once an active extract is identified by efficient in vitro assay and similar assay-guided fractionation has revealed the class of molecules or the molecule that is responsible, determination of effects in vivo is of interest. Using culture models such as the PC12 primary neuronal cells or the SH-SY5Y neuroblastoma cell line, effects of active molecules can be determined. In a first approach, cells can be treated by transfection or other means to harbour high levels of the protein of interest and then the effect of active molecules on cell survival can be measured using one of several commercially available assays for dead cells, which measure lactate dehydrogenase leakage or other indicative parameters. However, more precise information can be gleaned by histological analysis using stains such as Congo red or thioflavin S, described above, that reveal the presence of amyloid accumulation. Immunohistochemistry using appropriate antibodies against $\mathrm{A} \beta$ or $\alpha \mathrm{S}$ can be even more informative, as some allow distinction of oligomeric denatured forms from amyloid fibrils.

Cell-based assays can also provide an indication of the possibility of a molecule crossing the blood-brain barrier. Although $\mathrm{A} \beta$ circulates in the serum [54] and $\alpha \mathrm{S}$ is expressed in red blood cells [55], it is considered preferable for a compound to have direct access to the brain where the pathology takes place. Therefore, blood-brain barrier models in cell culture, such as the MDR-MCCK monolayer [56], are available to predict the permeability for specific substances. Nonetheless, blood brain barrier physiology is more complex than the models or direct plasma/brain ratio determinations would predict [57]. For that reason, results must be interpreted with care.

Animal models provide critical understanding in terms of the distribution, mode of action and effectiveness of an active molecule. Besides the well-known mouse models for many neurodegenerative diseases, there are valuable invertebrate and fish models. An $\alpha$ S-transgenic Drosophila fly model is available for PD [58] and an A $\beta$-transgenic model for AD [59] The nematode worm, Caenorhabditis elegans, can be used to study AD and PD [60, 61]. Zebrafish (Danio rerio) have an A $\beta$ protein precursor-encoding gene [62] and synuclein genes have been identified in this species [63]. Zebrafish may also become informative for studies of $\alpha \mathrm{S}$ once the encoded proteins in this organism are better understood.

\section{Protein folding modulators from common terrestrial natural products}

A large number of molecules have been shown to influence the aggregation of $A \beta[18]$ and a growing number have shown effects on $\alpha \mathrm{S}$ (discussed below). Although no effective therapy for PD or AD has emerged to date, progress on a number of natural products is encouraging. This situation is not surprising, as synthetic and combinatorial chemistry normally rely on a limited number of structural scaffolds and random permutations of structures and synthesizable units [64]. In contrast, natural molecules are highly diverse and they have been subject to evolutionary pressure under distinct conditions in which valuable activities 
have been selected. Therefore, they may offer a combination of variety and biological preselection that may make a therapeutic activity more likely [64].

\subsection{Natural protein folding modulators from terrestrial sources}

Several natural molecules have garnered interest because they modulate amyloid formation by $\mathrm{A} \beta$ (reviewed in $[18,65,66]$ ). A number of salient examples involving $\mathrm{A} \beta$ and $\alpha \mathrm{S}$ are presented here.

\subsubsection{Curcumin}

Curcumin is a natural polyphenol found in the traditional Indian spice turmeric. This molecule has been extensively investigated, in part because of its role in traditional Ayurvedic medicine [67]. Numerous studies have shown curcumin to have wide ranging biological activities, including $A \beta$ folding modulation. Curcumin shows promising interaction with $A \beta$. For example, using an oligomer-specific antibody for immunoblotting, cucurmin was found prevent $A \beta$ oligomerization and toxicity in vitro. In the same study, curcumin was shown to bind to amyloid plaques in brain sections of mice transgenic for the human amyloid precursor protein [68]. In addition, mature fibrils of the slightly shorter $A \beta_{40}$ peptide were destabilized by curcumin [68]. Curcumin and other polyphenols, including tannic acid, rosmarinic acid, and myricetin, were shown to inhibit fibril formation and destabilized mature fibrils for both $\mathrm{A} \beta$ and $\alpha \mathrm{S}$ [69]. As a result, curcumin has been a component of interest in clinical trials and, most recently the exclusive molecule in a trial for prevention of early cognitive decline and abnormal $A \beta$ accumulation in the brain [70]. If an effect is observed, it would be interesting to see if it acts directly upon misfolding at the dosage used in subjects.

\subsubsection{Epigallocatechin-3-gallate}

In terms of bioactive molecules in traditional medicine, perhaps the most recognized is (-)epigallocatechin 3-gallate (EGCG) that is found in unfermented (green) tea (Camellia sinensis). EGCG is a pleiotropic polyphenolic molecule with interesting protein folding modulation activity. In C. elegans expressing human $A \beta$ in muscle cells, western blotting analysis using an anti-A $\beta$ antibody showed EGCG to inhibit A $\beta$ oligomerization [71]. Studies of A $\beta$ and $\alpha$ S using ThT fluorescence, electron microscopy and other biophysical methods showed interaction with EGCG and ensuing "off-pathway" aggregation into spherical oligomers, which thereby prevented the formation of typical aggregation intermediates and amyloid fibrils by both proteins [25]. Further investigation revealed EGCG to bind directly to the $\beta$-sheet structure in the amyloid fibrils formed by $\mathrm{A} \beta$ and by $\alpha \mathrm{S}$ and to direct their rearrangement into smaller non-toxic protein aggregates [26]. A clinical trial is planned to examine the effect of EGCG on early stage $\mathrm{AD}$ [72] and this may have effects based upon the protein folding modulation described here, other properties of the molecule, or a combination thereof if adequate levels are attained in the brain. Other tea compounds may offer similar protection. Theaflavins are formed by oxidation of EGCG during the fermentation process to produce black tea. These derivatives were shown to have similar activity to EGCG in modulating the polymerization of $\mathrm{A} \beta$ and $\alpha \mathrm{S}$ [73]. 


\subsubsection{Carotenoids and related molecules}

Carotenoids (pro-vitamin A) and vitamin A are present in many commonly consumed foods. The in vitro examination of vitamin $A$ and $\beta$-carotene activity on $A B$ fibril formation, as measured using dye binding and electron microscopy suggest protective effects that appear to result from binding to a region in the C-terminal half of the peptide [74, 75]. This is consistent with reports that vitamin $\mathrm{A}$ and related molecules inhibit the progression of AD symptoms [76]. Also using dye binding and electron microscopy, vitamin A and $\beta$-carotene were shown to inhibit the formation of $\alpha \mathrm{S}$ amyloid fibrils and to destabilize existing fibrils [77].

\subsubsection{Scyllo-inositol}

Another natural molecule that has garnered interest is scyllo-inositol, which is abundant in the coconut palm (Cocos nucifera) [78]. Scyllo-inositol is a stereoisomer of myo-inositol that stabilizes a non-toxic oligomeric aggregate of $\mathrm{A} \beta$ [78-80]. This is in contrast to phosphatidylinositol, which was found to promote fibrillogenesis and membrane insertion of $A \beta$ [78]. Scylloinositol also protected against $A \beta$ oligomer-induced inhibition of long-term potentiation [80]. A clinical trial of scyllo-inositol was inconclusive after the highest doses were discontinued [81]. Nonetheless, it remains a compound of interest provided that drawbacks can be addressed.

\subsubsection{Emerging sources}

In addition to the well-studied molecules above, there are growing possibilities for other sources of folding modulators. For example, another source of interesting polyphenols is the wolf berry, Lycium barbarum, which is used in traditional Chinese medicine and was shown to protect against $\mathrm{A} \beta$-related cell death [82]. Extracts obtained from other species used in traditional Chinese medicine, including cat's claw (Uncaria rhynchophylla) and tree peony (Paeonia suffruticosa) have shown relevant activity [83-85]. The tree peony contains 1,2,3,4,6penta-O-galloyl-beta-D-glucopyranose, which prevented $\mathrm{A} \beta$ fiber formation and reversed the process in existing fibers [84]. In addition, other polyphenols procyanidins from apple (Malus domestica), silymarin from thistle (Carduus marianus) and reservatrol from red grapes (Vitis $s p$.) show interesting activities that may warrant further study [86-88].

\subsection{Challenges with natural folding modulators}

Although much attention has been brought to the natural folding modulators present in various terrestrial species, none have yet translated into meaningful therapies. The best prospect currently appears to be EGCG [89], which nonetheless presents challenges.

\subsubsection{Challenges in delivery of natural products}

EGCG is susceptible to decomposition during storage prior to being consumed, much of it may be destroyed by normal stomach acid during digestion, it is not highly bioavailable and it carries the possibility of hepatotoxicity (reviewed in [90]). Therefore, ideal handling, delivery and dosage would need to be determined before this molecule could be employed successfully 
to manage disease-related misfolding in animals or humans. Nonetheless, studies have suggested that the use of green tea is negatively correlated to the prevalence of cognitive impairment [91] and that tea shows a dose-dependent effect in protection from PD [92]. Therefore, even with regular storage, preparation and consumption of tea as part of a normal diet, it appears that tea components, and likely EGCG or its derived theaflavins, have a measure of benefit. It is not yet clear whether the reported benefits involve the modulation of protein misfolding, and this would be an area for future study. Curcumin presents challenges similar to those of EGCG and derivatives. Dietary ingestion of curcumin appears sufficient to offer some measure of protection from neurodegenerative diseases in populations that consume it (reviewed in [93]), suggesting its bioavailability. Yet, bioavailability was found to be limiting and work has been undertaken toward improving delivery of curcumin by combining it with phosphatidyl choline, olive oil and stearic acid [94]. Similarly, plasma levels of EGCG following oral consumption were higher when the product was encapsulated in chitosan nanoparticles [95]. The promising suggestion is that formulation and delivery may be optimized to enhance availability of these protein folding modulators in vivo. Other compounds such as carotenoids are bioavailable and cross the blood-brain barrier as well, possibly making them convenient for the establishment of protein folding modulators [96].

\subsubsection{Requirement for crossing the blood-brain barrier}

It is widely accepted that molecules must cross the blood-brain barrier in order to have relevant biological effects on neurodegenerative diseases; however, interesting new findings are suggesting that this may not always be the case. In a study using radiolabeled $A \beta_{40}$ administered to the brains of rats, elevated peripheral $A \beta_{40}$ levels reduced protein clearance from the brain [97]. Conversely, a decline of $A \beta$ levels in blood plasma can lead to cognitive improvement, presumably by reducing $A \beta$ levels in the brain $[98,99]$. Furthermore, genetic study of the presenilin gene encoding a secretase with a role in $A \beta$ synthesis revealed a heritable expression level in the liver, suggesting a role of liver-expressed protein in brain $A \beta$ levels [100]. Follow-up investigation using ST571, a drug that lowers peripheral A $\beta$ levels but that does not cross the blood-brain barrier, showed reduction in brain $A \beta$ [100]. Although these were studies of complete $A \beta$ levels rather than the different conformations and aggregates, together they do imply that modulation of peripheral oligomerized and fibrillar forms of $A \beta$, which would facilitate clearance, could affect the brain ratios of differently associated A $\beta$ forms. Therefore, protein folding modulators that do not cross the blood-brain barrier may still be worth considering in the prevention and treatment of disease. These studies have the drawback of assuming a stable and functional blood-brain barrier over the course of these diseases; however, other findings suggest that functioning of the blood-brain barrier may become compromised over the course of $\mathrm{AD}$ and other neurodegenerative diseases (reviewed in [101]), which may result in inappropriate dosages of molecules from plasma. Therefore, the prevention phase may be critical to the benefit of any molecule that acts peripherally to modulate $A \beta$, as that is the point at which normal transfer of molecules such as $A \beta$ across the barrier can occur. Alternatively, the compromised blood-brain-barrier during the disease phase may allow therapeutic molecules to reach the brain more efficiently. These possibilities require further study. 


\section{Marine possibilities for natural protein folding modulators}

Natural products from the land include promising as sources of novel protein folding modulators for the reasons outlined earlier. By extension, marine sources may hold proportionally greater opportunity for discovery than their terrestrial counterparts because, until this decade, much of the ocean biota was unexplored. The Census of Marine Life uncovered remarkable and previously unknown plant and animal biodiversity in the oceans (reviewed in [102]). In the Gulf of Maine alone, the current species count identifies at least 652 fish species, 184 species of birds, 733 different species of microscopic plants and algae and 32 mammalian species [103]. Microbial diversity is also extensive worldwide, as inferred from the large number of new protein families uncovered from marine microbes [104].

Marine resources offer largely untapped diversity that may offer new options for natural product development [105]. Only six marine natural products and 14 synthetic compounds based upon the structures of natural marine products are FDA-approved agents or in clinical trial (reviewed in [106]). However, this list is likely to grow. In 2010, 895 new citations were reported on marine-derived compounds [107]. Marine species are already being examined for molecules that inhibit $\beta$-secretase 1 , an enzyme that processes the amyloid precursor protein to give $\mathrm{A} \beta$ and other fragments [108]. Nonetheless, the development of inhibitors has been very difficult elsewhere [108] and there may be other biological consequences to the modulation of this enzyme. Therefore, it is ideal to focus more specifically on protein misfolding, which appears to be the linchpin in most of the neurodegenerative diseases. There is a wide variety of challenging and variable marine environments that would naturally select for traits that include protein folding modulation due to temperature or pressure, chemical defense molecules and other products that may be undersampled or undiscovered because of accessibility. Marine plants and sessile marine animals may produce chemical defenses that are remarkable in comparison to those of species that can move away from danger. In addition, species that inhabit highly variable or extreme environments, such as freezing waters, have adaptations to maintain proteostasis during exposure to extreme temperatures and solution properties [109-111]. For these reasons, they may represent ideal sources of natural molecules to prevent or ameliorate protein misfolding.

The discovery, characterization and production of marine-derived molecules appears promising, but with complexity and risk, nonetheless. A general overview of the process is shown in Fig. 2.

\subsection{Natural protein folding modulators from marine sources}

\subsubsection{Marine polyphenols}

Polyphenols are abundant and varied in marine algal species (reviewed in [112]). Like their terrestrial counterparts, algal polyphenols have shown folding modulation of $\mathrm{A} \beta$. The brown seaweed (macroalgae) Ecklonia cava is found in the waters around Japan and Korea, where it is used as a herbal remedy. A butanol extract from E. cava has been shown to prevent production and aggregation of $A \beta$ and to reduce amyloid plaques [113]. Electron microscopy showed 
the $\mathrm{A} \beta$ oligomers to be reduced and dye binding as well, indicating an inhibition of fibril formation. The polyphenolic phlorotannins are considered to be the active compounds responsible for the biological activities of E. cava [114, 115]. Nonetheless, other molecules cannot be strictly ruled out [113].

\section{Discovery}

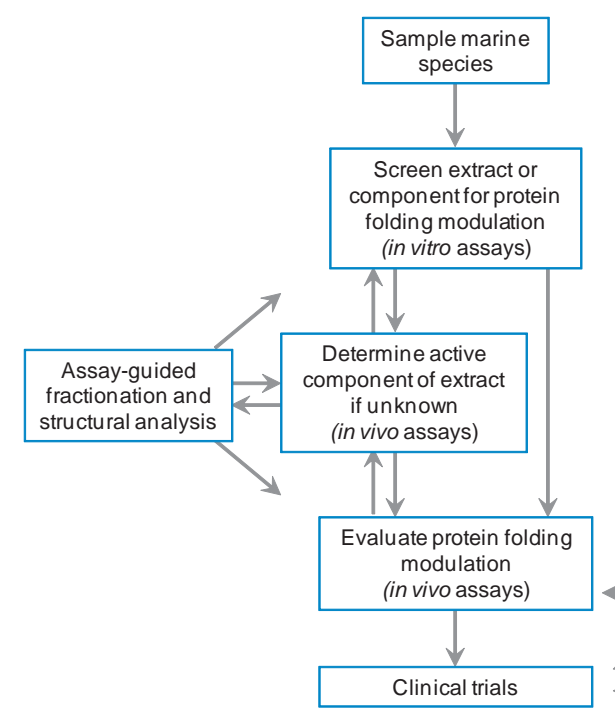

Production

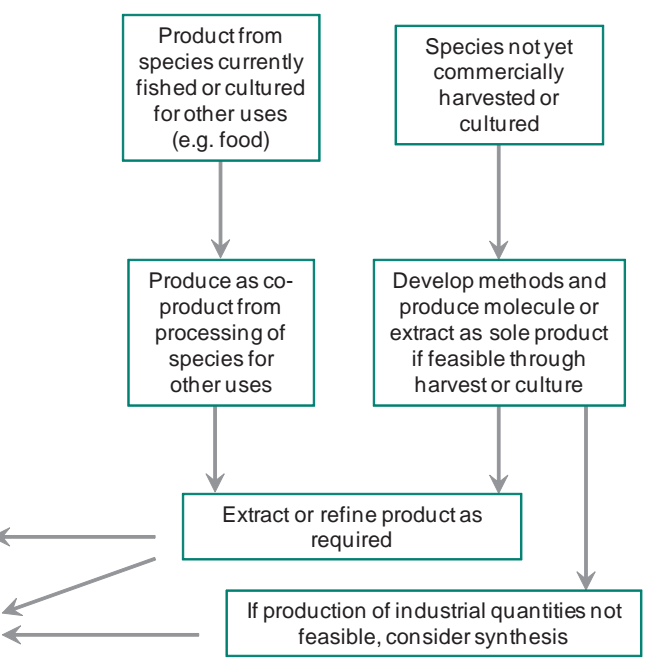

Figure 2. Schematic summary of key steps in the identification and development of marine-sourced protein folding modulators. Blue boxes are steps involved in discovery and characterization of protein folding modulation and the molecule responsible. Green boxes are steps involved in production of the molecule (or of an extract containing it). For more detail, see chapter text. Structural elucidation is not included here as it is not covered in this chapter; it is covered in another chapter of this book.

\subsubsection{Marine carotenoids}

Marine algae and invertebrates harbour large quantities of carotenoids. This is of interest because, as noted above, carotenoids are among the molecules showing promise in modulation of protein misfolding. Algal carotenoids are widely varied (reviewed in [112]). These appear to be particularly accessible through enzyme-assisted extraction (reviewed in [116]) and they may have interesting activities. Shrimp and crab processing wastes are also excellent sources of carotenoids. Crustacean shells left over during processing contain the carotenoid astaxanthin (reviewed in [112]), which gives them their striking colour. This is in addition to the chitin in the shells, and its component glucosamine, which is well known in other contexts. There are no reports of evaluation of marine-derived carotenoids in protein folding modulation, as there are for terrestrial counterparts. With the numerous and varied sources of marine carotenoids, these could be compared with terrestrial versions previously reported to modulate protein folding. 


\subsubsection{Marine toxins}

There is a plethora of marine toxins with distinctive neurological effects. These toxins are mainly known for the poisoning risk they carry. Nonetheless, a few of them have valuable biological activities as research chemicals and one has intriguing effects relative to AD. Using cell-based assays, the toxin 13-desmethyl spirolide $C$ from the dinoflagellate Alexandrium ostenfeldii was shown to reduce $\mathrm{A} \beta$ accumulation in cells by just over $40 \%$ [117]. The antibody used (6E10, Covance) detects $\mathrm{A} \beta$ without distinguishing between monomeric or oligomeric or fibril forms. It would therefore be valuable to repeat these analyses using fold-specific anti$\mathrm{A} \beta$ antibodies or another fold-sensitive method to see if any effect there could be detected. Otherwise, it may act on $A \beta$ in other beneficial ways that would also be of interest.

\subsubsection{Marine-sourced chemical chaperones and conflicting results}

A variety of chemical chaperones, which are loosely defined as small molecules that promote folding of many proteins, have gained interest in terms of wide-spectrum protection of proteins from misfolding (reviewed in [118]). In marine species faced with protein misfolding risk, the accumulation of one or more chemical chaperones is a common adaptation because these small chaperoning molecules promote general proteostasis [111, 119]. Therefore, at first glance, these molecules would appear to be ideal in terms of proteins such as $\mathrm{A} \beta$ and $\alpha \mathrm{S}$. They could be produced naturally or synthetically, depending upon their molecular features, and they may stabilize many different proteins. However, some chemical chaperones may have problematic effects with respect to amyloidotic protein misfolding. Glycerol at supraphysiological concentrations (molar range) and trimethylamine oxide (TMAO) at moderate concentrations were both shown to favour the transition of $A \beta$ from its unfolded conformation to the $\beta$-sheet form requisite for fiber formation [120]. Protofibril to fibril conversion was also enhanced [120]. The situation appears more complex for $\alpha$, with elevated concentrations (molar range) of TMAO favouring a partially folded form with high propensity for fibril formation and even higher concentrations of TMAO favouring an oligomeric $\alpha$-helical conformation [121], which may be consistent with a native $\alpha$-helical form of the protein that resists misfolding [29]. Although these chaperone concentrations used were far in excess of those that would be reached in vivo, the effects suggest a possibility to be aware of if a novel folding modulator appears to be non-specific. Stabilization by chemical chaperones may bring an increased risk of aggregation for some proteins [119]. Furthermore, stabilization of a wider range of cell proteins or protein complexes may cause unanticipated problems. Therefore, examination of unusual and offtarget effects would be prudent in the evaluation of chemical chaperones.

\subsection{Sources for marine products}

A challenge presented by many rare or remote marine species that may produce pharmaceutical or nutraceutical molecules is the difficulty in obtaining sufficient product in a sustainable manner, from both the environmental and economic standpoints [122]. Options for these products include the development of culture methods for the species or synthesis of the molecule, although in many cases the molecules are too complex to be efficiently synthesized $[122,123]$. In contrast, an advantage for nutraceutical or drug development from many 
accessible marine species, both plant and animal, is that they are already supplied as human food sources. Additionally, a large number of marine species are currently farmed, and availability of a standard supply for natural product development would be more straightforward and predictable than it would be for their wild counterparts. Sustainable production or harvesting of species for natural marine products would be a key consideration in production of folding modulators, just as it is for the production of foods.

In the case of some seaweeds, marine harvesting can be carried out. However, on-land cultivation offers the additional benefits of ideal traceability and process control, albeit with substantial costs [124]. For microalgae, this would be the only option. Algal processing wastes are significant and they are of interest for the development of by-products [125].

For commercially fished animal species, processing for food production is a frequent practice. These wild finfish and shellfish species, as well as those grown in aquaculture, can generate substantial waste during processing for food production and this waste often go to landfills or composting. The identification of valuable properties or activities in waste materials allows them to be used to produce co-products and, with green chemistry initiatives, these could be produced in a sustainable fashion from a healthy wild harvesting or aquaculture operation. There is growing interest in co-product development, as highlighted by two contrasting examples. Snow crab (Chionoecetes opilio) are fished across the Maritime provinces of Canada. Crab processing waste currently contributes to landfills, but the potential for additional product development with the identification of sufficiently valuable uses is being considered [126] as is the case elsewhere, likely based upon chitin but possibly upon other products as well. Innovative solutions to waste challenges are also being pursued in salmon aquaculture. Integrated multi-trophic aquaculture of Atlantic salmon (Salmo salar) with macroalgal species and mussels (Mytilus edulis) in the Bay of Fundy, Canada, minimizes waste accumulation by allowing nutrient and resource recovery with diminished impact on the local environment and this process is advancing toward commercial production [127]. The economic viability of this integration initiative will rely upon the development of foods along with other high-value products from the cultured species [128]. A neuroprotective protein folding modulator from such a resource could enhance markets for the food, while offering the possibility of producing sustainable nutraceuticals and eventual pharmaceuticals as co-products if appropriate.

\section{Conclusions}

With protein misfolding identified as a causative event in multiple neurodegenerative diseases and with no definitive means of prevention or cure in place, the progress being made in the discovery and development of natural protein misfolding modulators is of great interest. Although several promising leads from terrestrial sources have been identified, none have been shown to provide a clear result in disease outcome to date. Therefore, while current products are being developed and refined, it would be logical to investigate a wider range of sources for protein folding modulators. In this context, marine species deserve a second (or, in some cases, a first) look. 
There has already been extensive work on marine molecules from some sources, but crucial to the proposed endeavour is screening for the most relevant activities. For example, testing marine molecules or extracts for effects in model $\mathrm{A} \beta$ or $\alpha \mathrm{S}$ cell survival assays may not indicate protein folding modulation. However, the reverse is likely to be true in most cases. In other words, appropriate protein folding modulation activity should lead to enhanced cell survival. It is also important to be mindful of assay subtleties. Testing for anti-fibrillization activity may uncover molecules that cause toxic oligomers to accumulate instead of amyloid fibrils, leading to increased pathology instead of amelioration. Similarly, searching for molecules that bring about a reduction in total $\mathrm{A} \beta$ ( or $\alpha \mathrm{S}$ ) may not be prudent, as we have little understanding of the normal roles of these proteins in the brain and therefore drastic reduction in levels may have undesirable consequences [18]. For these reasons, an assay suite that allows determination of toxic oligomers as well as other (non-toxic) oligmers, monomers, amyloid fibrils and other aggregates would be ideal. In order to identify a marine extract or molecule that provides protective protein folding modulation, the spectrum of its effects on protein misfolding and association protein would need to be investigated. Furthermore, because a number of natural molecules appear to affect the misfolding trajectories of both $\mathrm{A} \beta$ and $\alpha \mathrm{S}$, these would be of particular interest because of the potential for wider-ranging protection from toxic misfolding.

In closing, examination of marine biota for protein folding modulators using a suitable suite of assays may offer a promising opportunity to identify a safe, effective and sustainable protein folding modulator that addresses the cause of a neurodegenerative disease. The untapped diversity of marine species combined with a rational selection of assays for folding modulator identification based upon examples used in terrestrial investigations and coupled with appropriate downstream in vivo analysis would be ideal. For proteins such as $\mathrm{A} \beta$ and $\alpha \mathrm{S}$, which form similar amyloids and can even cross-seed in spite of their structural differences [129], a further tantalizing prospect would be the identification of a molecule that would be effective for both $\mathrm{AD}$ and PD. Given the paucity of treatments currently available, discovery of an active molecule from a marine resource could bring hope at this time.

\section{Acknowledgements}

We thank Dr. Stephen Ewart (Novaceutics Consulting) for his helpful review of the manuscript. Research on protein misfolding in the laboratory of K.V. Ewart is supported by the National Research Council of Canada and by an NSERC Discovery grant.

\section{Author details}

James C. Giffin ${ }^{1}$ and Kathryn Vanya Ewart ${ }^{2}$

1 Department of Biology, Dalhousie University, Halifax, Canada

2 National Research Council Aquatic and Crop Resource Development, Halifax, Canada 


\section{References}

[1] Chen B, Retzlaff M, Roos T, Frydman J. Cellular strategies of protein quality control. Cold Spring Harb Perspect Biol 2011; 3 a004374.

[2] Herczenik E, Gebbink MF. Molecular and cellular aspects of protein misfolding and disease. Faseb J 2008; 22 2115-2133.

[3] Uversky VN. Intrinsic disorder in proteins associated with neurodegenerative diseases. Front Biosci 2009; 14 5188-5238.

[4] Rakhit R, Cunningham P, Furtos-Matei A, Dahan S, Qi XF, Crow JP, Cashman NR, Kondejewski LH, Chakrabartty A. Oxidation-induced misfolding and aggregation of superoxide dismutase and its implications for amyotrophic lateral sclerosis. J Biol Chem 2002; 277 47551-47556.

[5] Guest WC, Silverman JM, Pokrishevsky E, O'Neill MA, Grad LI, Cashman NR. Generalization of the prion hypothesis to other neurodegenerative diseases: an imperfect fit. J Toxicol Environ Health A 2011; 74 1433-1459.

[6] Harrison RS, Sharpe PC, Singh Y, Fairlie DP. Amyloid peptides and proteins in review. Rev Physiol Biochem Pharmacol 2007; 159 1-77.

[7] Morales R, Green KM, Soto C. Cross currents in protein misfolding disorders: interactions and therapy. CNS Neurol Disord Drug Targets 2009; 8 363-371.

[8] Aguzzi A, O'Connor T. Protein aggregation diseases: pathogenicity and therapeutic perspectives. Nat Rev Drug Discov 2010; 9 237-248.

[9] Lee SJ, Lim HS, Masliah E, Lee HJ. Protein aggregate spreading in neurodegenerative diseases: problems and perspectives. Neurosci Res 2011; 70 339-348.

[10] Andrew SE, Goldberg YP, Kremer B, Telenius H, Theilmann J, Adam S, Starr E, Squitieri F, Lin B, Kalchman MA, et al. The relationship between trinucleotide (CAG) repeat length and clinical features of Huntington's disease. Nat Genet 1993; 4 398-403.

[11] Duyao M, Ambrose C, Myers R, Novelletto A, Persichetti F, Frontali M, Folstein S, Ross C, Franz M, Abbott M, et al. Trinucleotide repeat length instability and age of onset in Huntington's disease. Nat Genet 1993; 4 387-392.

[12] Snell RG, MacMillan JC, Cheadle JP, Fenton I, Lazarou LP, Davies P, MacDonald ME, Gusella JF, Harper PS, Shaw DJ. Relationship between trinucleotide repeat expansion and phenotypic variation in Huntington's disease. Nat Genet 1993; 4 393-397.

[13] Walters RH, Murphy RM. Examining polyglutamine peptide length: a connection between collapsed conformations and increased aggregation. J Mol Biol 2009; 393 978-992. 
[14] Liscic RM, Breljak D. Molecular basis of amyotrophic lateral sclerosis. Prog Neuropsychopharmacol Biol Psychiatry 2011; 35 370-372.

[15] Brundin P, Melki R, Kopito R. Prion-like transmission of protein aggregates in neurodegenerative diseases. Nat Rev Mol Cell Biol 2010; 11 301-307.

[16] Jucker M, Walker LC. Pathogenic protein seeding in Alzheimer disease and other neurodegenerative disorders. Ann Neurol 2011; 70 532-540.

[17] Nussbaum RL, Ellis CE. Alzheimer's disease and Parkinson's disease. N Engl J Med 2003; 348 1356-1364.

[18] Carter MD, Simms GA, Weaver DF. The development of new therapeutics for Alzheimer's disease. Clin Pharmacol Ther 2010; 88 475-486.

[19] Goate A, Chartier-Harlin MC, Mullan M, Brown J, Crawford F, Fidani L, Giuffra L, Haynes A, Irving N, James L, et al. Segregation of a missense mutation in the amyloid precursor protein gene with familial Alzheimer's disease. Nature 1991; 349 704-706.

[20] Sherrington R, Rogaev EI, Liang Y, Rogaeva EA, Levesque G, Ikeda M, Chi H, Lin C, Li G, Holman K, Tsuda T, Mar L, Foncin JF, Bruni AC, Montesi MP, Sorbi S, Rainero I, Pinessi L, Nee L, Chumakov I, Pollen D, Brookes A, Sanseau P, Polinsky RJ, Wasco W, Da Silva HA, Haines JL, Perkicak-Vance MA, Tanzi RE, Roses AD, Fraser PE, Rommens JM, St George-Hyslop PH. Cloning of a gene bearing missense mutations in early-onset familial Alzheimer's disease. Nature 1995; 375 754-760.

[21] Hutton M, Perez-Tur J, Hardy J. Genetics of Alzheimer's disease. Essays Biochem $1998 ; 33$ 117-131.

[22] Hoehn MM, Yahr MD. Parkinsonism: onset, progression and mortality. Neurology $1967 ; 17$ 427-442.

[23] Breydo L, Wu JW, Uversky VN. $\alpha$-synuclein misfolding and Parkinson's disease. Biochim Biophys Acta 2012; 1822 261-285.

[24] Stefanis L. $\alpha$-Synuclein in Parkinson's disease. Cold Spring Harb Perspect Med 2012; 2 a009399.

[25] Ehrnhoefer DE, Bieschke J, Boeddrich A, Herbst M, Masino L, Lurz R, Engemann S, Pastore A, Wanker EE. EGCG redirects amyloidogenic polypeptides into unstructured, off-pathway oligomers. Nat Struct Mol Biol 2008; 15 558-566.

[26] Bieschke J, Russ J, Friedrich RP, Ehrnhoefer DE, Wobst H, Neugebauer K, Wanker EE. EGCG remodels mature $\alpha$-synuclein and amyloid- $\beta$ fibrils and reduces cellular toxicity. Proc Natl Acad Sci U S A 2010; 107 7710-7715.

[27] Nelson R, Eisenberg D. Structural models of amyloid-like fibrils. Adv Protein Chem 2006; 73 235-282. 
[28] Jarvet J, Danielsson J, Damberg P, Oleszczuk M, Graslund A. Positioning of the Alzheimer A $\beta(1-40)$ peptide in SDS micelles using NMR and paramagnetic probes. J Biomol NMR 2007; 39 63-72.

[29] Bartels T, Choi JG, Selkoe DJ. alpha-Synuclein occurs physiologically as a helically folded tetramer that resists aggregation. Nature 2011; 477 107-110.

[30] Wang W, Perovic I, Chittuluru J, Kaganovich A, Nguyen LT, Liao J, Auclair JR, Johnson D, Landeru A, Simorellis AK, Ju S, Cookson MR, Asturias FJ, Agar JN, Webb BN, Kang C, Ringe D, Petsko GA, Pochapsky TC, Hoang QQ. A soluble $\alpha$-synuclein construct forms a dynamic tetramer. Proc Natl Acad Sci U S A 2011; 108 17797-17802.

[31] Nerelius C, Sandegren A, Sargsyan H, Raunak R, Leijonmarck H, Chatterjee U, Fisahn A, Imarisio S, Lomas DA, Crowther DC, Stromberg R, Johansson J. Alpha-helix targeting reduces amyloid- $\beta$ peptide toxicity. Proc Natl Acad Sci U S A 2009; 106 9191-9196.

[32] Ito M, Johansson J, Stromberg R, Nilsson L. Unfolding of the amyloid $\beta$-peptide central helix: mechanistic insights from molecular dynamics simulations. PLoS One 2011; 6 e17587.

[33] Whitmore L, Wallace BA. DICHROWEB, an online server for protein secondary structure analyses from circular dichroism spectroscopic data. Nucleic Acids Res 2004; 32 W668-673.

[34] Nettleship JE, Brown J, Groves MR, Geerlof A. Methods for protein characterization by mass spectrometry, thermal shift (ThermoFluor) assay, and multiangle or static light scattering. Methods Mol Biol 2008; 426 299-318.

[35] LeVine H, 3rd. Quantification of $\beta$-sheet amyloid fibril structures with thioflavin T. Methods Enzymol 1999; 309 274-284.

[36] Vassar PS, Culling CF. Fluorescent stains, with special reference to amyloid and connective tissues. Arch Pathol 1959; 68 487-498.

[37] Puchtler H, Sweat F, Levine M. On the binding of Congo red by amyloid. J Histochem Cytochem 1962; 10 355-364.

[38] Hawe A, Sutter M, Jiskoot W. Extrinsic fluorescent dyes as tools for protein characterization. Pharm Res 2008; 25 1487-1499.

[39] Bertoncini CW, Celej MS. Small molecule fluorescent probes for the detection of amyloid self-assembly in vitro and in vivo. Curr Protein Pept Sci 2011; 12 205-220.

[40] Reinke AA, Abulwerdi GA, Gestwicki JE. Quantifying prefibrillar amyloids in vitro by using a "thioflavin-like" spectroscopic method. Chembiochem 2010; 11 1889-1895.

[41] Lee JH, Lee IH, Choe YJ, Kang S, Kim HY, Gai WP, Hahn JS, Paik SR. Real-time analysis of amyloid fibril formation of $\alpha$-synuclein using a fibrillation-state-specific fluorescent probe of JC-1. Biochem J 2009; 418 311-323. 
[42] Kovacs GG, Wagner U, Dumont B, Pikkarainen M, Osman AA, Streichenberger N, Leisser I, Verchere J, Baron T, Alafuzoff I, Budka H, Perret-Liaudet A, Lachmann I. An antibody with high reactivity for disease-associated $\alpha$-synuclein reveals extensive brain pathology. Acta Neuropathol 2012; 124 37-50.

[43] Perchiacca JM, Ladiwala AR, Bhattacharya M, Tessier PM. Structure-based design of conformation- and sequence-specific antibodies against amyloid $\beta$. Proc Natl Acad Sci U S A 2012; 109 84-89.

[44] Yam AY, Wang X, Gao CM, Connolly MD, Zuckermann RN, Bleu T, Hall J, Fedynyshyn JP, Allauzen S, Peretz D, Salisbury CM. A universal method for detection of amyloidogenic misfolded proteins. Biochemistry 2011; 50 4322-4329.

[45] Zurdo J. Polypeptide models to understand misfolding and amyloidogenesis and their relevance in protein design and therapeutics. Protein Pept Lett 2005; 12 171-187.

[46] Graether SP, Slupsky CM, Sykes BD. Freezing of a fish antifreeze protein results in amyloid fibril formation. Biophys J 2003; 84 552-557.

[47] Graether SP, Sykes BD. Structural characterization of amyloidotic antifreeze protein fibrils and intermediates. J Toxicol Environ Health A 2009; 72 1030-1033.

[48] Dube A, Investigation of antifreeze protein activity in blue mussels and amyloid-like transition in a predominant winter flounder serum antifreeze protein, Graduate thesis, Dalhousie University, Halifax, Canada, 2012; 224 p.

[49] Guo JP, Yu S, McGeer PL. Simple in vitro assays to identify amyloid- $\beta$ aggregation blockers for Alzheimer's disease therapy. J Alzheimers Dis 2010; 19 1359-1370.

[50] Arslan PE, Chakrabartty A. Probing Alzheimer amyloid peptide aggregation using a cell-free fluorescent protein refolding method. Biochem Cell Biol 2009; 87 631-639.

[51] Kryndushkin DS, Alexandrov IM, Ter-Avanesyan MD, Kushnirov VV. Yeast [PSI+] prion aggregates are formed by small Sup35 polymers fragmented by Hsp104. J Biol Chem 2003; 278 49636-49643.

[52] Halfmann R, Lindquist S. Screening for amyloid aggregation by semi-denaturing detergent-agarose gel electrophoresis. J Vis Exp 2008; 16838.

[53] Kim W, Kim Y, Min J, Kim DJ, Chang YT, Hecht MH. A high-throughput screen for compounds that inhibit aggregation of the Alzheimer's peptide. ACS Chem Biol 2006; 1 461-469.

[54] Seeman P, Seeman N. Alzheimer's disease: $\beta$-amyloid plaque formation in human brain. Synapse 2011; 65 1289-1297.

[55] Barbour R, Kling K, Anderson JP, Banducci K, Cole T, Diep L, Fox M, Goldstein JM, Soriano F, Seubert P, Chilcote TJ. Red blood cells are the major source of alpha-synuclein in blood. Neurodegener Dis 2008; 5 55-59. 
[56] Wang Q, Rager JD, Weinstein K, Kardos PS, Dobson GL, Li J, Hidalgo IJ. Evaluation of the MDR-MDCK cell line as a permeability screen for the blood-brain barrier. Int J Pharm 2005; 288 349-359.

[57] Jeffrey P, Summerfield SG. Challenges for blood-brain barrier (BBB) screening. Xenobiotica 2007; 37 1135-1151.

[58] Mizuno H, Fujikake N, Wada K, Nagai Y. $\alpha$-Synuclein Transgenic Drosophila As a Model of Parkinson's Disease and Related Synucleinopathies. Parkinsons Dis 2010; 2011212706.

[59] Iijima-Ando K, Iijima K. Transgenic Drosophila models of Alzheimer's disease and tauopathies. Brain Struct Funct 2010; 214 245-262.

[60] Kuwahara T, Koyama A, Gengyo-Ando K, Masuda M, Kowa H, Tsunoda M, Mitani S, Iwatsubo T. Familial Parkinson mutant alpha-synuclein causes dopamine neuron dysfunction in transgenic Caenorhabditis elegans. J Biol Chem 2006; 281 334-340.

[61] Link CD. C. elegans models of age-associated neurodegenerative diseases: lessons from transgenic worm models of Alzheimer's disease. Exp Gerontol 2006; 41 1007-1013.

[62] Xia W. Exploring Alzheimer's disease in zebrafish. J Alzheimers Dis 2010; 20 981-990.

[63] Sun Z, Gitler AD. Discovery and characterization of three novel synuclein genes in zebrafish. Dev Dyn 2008; 237 2490-2495.

[64] Hunter P. Harnessing nature's wisdom. turning to nature for inspiration and avoiding her follies. EMBO Rep 2008; 9 838-840.

[65] Kim J, Lee HJ, Lee KW. Naturally occurring phytochemicals for the prevention of Alzheimer's disease. J Neurochem 2010; 112 1415-1430.

[66] Park SY. Potential therapeutic agents against Alzheimer's disease from natural sources. Arch Pharm Res 2010; 33 1589-1609.

[67] Aggarwal BB, Sundaram C, Malani N, Ichikawa H. Curcumin: the Indian solid gold. Adv Exp Med Biol 2007; 595 1-75.

[68] Yang F, Lim GP, Begum AN, Ubeda OJ, Simmons MR, Ambegaokar SS, Chen PP, Kayed R, Glabe CG, Frautschy SA, Cole GM. Curcumin inhibits formation of amyloid $\beta$ oligomers and fibrils, binds plaques, and reduces amyloid in vivo. J Biol Chem 2005; $2805892-5901$.

[69] Ono K, Yamada M. Antioxidant compounds have potent anti-fibrillogenic and fibrildestabilizing effects for $\alpha$-synuclein fibrils in vitro. J Neurochem 2006; 97 105-115.

[70] Small G. Clinical Trial: 18-months study of curcumin. (http://clinicaltrials.gov/ct2/ show/study/NCT01383161?term=curcumin+alzheimer\%27s\&rank=5). 
[71] Abbas S, Wink M. Epigallocatechin gallate inhibits beta amyloid oligomerization in Caenorhabditis elegans and affects the daf-2/insulin-like signaling pathway. Phytomedicine 2010; 17 902-909.

[72] Friedemann P. Clinical trial: Sunphenon EGCG (epigallocatechin-gallate) in the early stage of Alzheimer's disease (SUN-AK). (http://clinicaltrials.gov/ct2/show/ NCT00951834).

[73] Grelle G, Otto A, Lorenz M, Frank RF, Wanker EE, Bieschke J. Black tea theaflavins inhibit formation of toxic amyloid- $\beta$ and $\alpha$-synuclein fibrils. Biochemistry 2011; 50 10624-10636.

[74] Ono K, Yoshiike Y, Takashima A, Hasegawa K, Naiki H, Yamada M. Vitamin A exhibits potent antiamyloidogenic and fibril-destabilizing effects in vitro. Exp Neurol 2004; 189 380-392.

[75] Takasaki J, Ono K, Yoshiike Y, Hirohata M, Ikeda T, Morinaga A, Takashima A, Yamada M. Vitamin A has anti-oligomerization effects on amyloid- $\beta$ in vitro. J Alzheimers Dis 2011; 27 271-280.

[76] Ono K, Yamada M. Vitamin A and Alzheimer's disease. Geriatr Gerontol Int 2012; 12 180-188.

[77] Ono K, Yamada M. Vitamin A potently destabilizes preformed alpha-synuclein fibrils in vitro: implications for Lewy body diseases. Neurobiol Dis 2007; 25 446-454.

[78] Dasilva KA, Shaw JE, McLaurin J. Amyloid- $\beta$ fibrillogenesis: structural insight and therapeutic intervention. Exp Neurol 2010; 223 311-321.

[79] McLaurin J, Golomb R, Jurewicz A, Antel JP, Fraser PE. Inositol stereoisomers stabilize an oligomeric aggregate of Alzheimer amyloid $\beta$ peptide and inhibit $A \beta$-induced toxicity. J Biol Chem 2000; 275 18495-18502.

[80] Townsend M, Shankar GM, Mehta T, Walsh DM, Selkoe DJ. Effects of secreted oligomers of amyloid $\beta$-protein on hippocampal synaptic plasticity: a potent role for trimers. J Physiol 2006; 572 477-492.

[81] Salloway S, Sperling R, Keren R, Porsteinsson AP, van Dyck CH, Tariot PN, Gilman S, Arnold D, Abushakra S, Hernandez C, Crans G, Liang E, Quinn G, Bairu M, Pastrak A, Cedarbaum JM. A phase 2 randomized trial of ELND005, scyllo-inositol, in mild to moderate Alzheimer disease. Neurology 2011; 77 1253-1262.

[82] Chang RC, So KF. Use of anti-aging herbal medicine, Lycium barbarum, against agingassociated diseases. What do we know so far? Cell Mol Neurobiol 2008; 28 643-652.

[83] Fujiwara H, Iwasaki K, Furukawa K, Seki T, He M, Maruyama M, Tomita N, Kudo Y, Higuchi M, Saido TC, Maeda S, Takashima A, Hara M, Ohizumi Y, Arai H. Uncaria rhynchophylla, a Chinese medicinal herb, has potent antiaggregation effects on Alzheimer's $\beta$-amyloid proteins. J Neurosci Res 2006; 84 427-433. 
[84] Fujiwara H, Tabuchi M, Yamaguchi T, Iwasaki K, Furukawa K, Sekiguchi K, Ikarashi Y, Kudo Y, Higuchi M, Saido TC, Maeda S, Takashima A, Hara M, Yaegashi N, Kase $\mathrm{Y}$, Arai H. A traditional medicinal herb Paeonia suffruticosa and its active constituent 1,2,3,4,6-penta-O-galloyl-beta-D-glucopyranose have potent anti-aggregation effects on Alzheimer's amyloid beta proteins in vitro and in vivo. J Neurochem 2009; 109 1648-1657.

[85] Xian YF, Lin ZX, Mao QQ, Hu Z, Zhao M, Che CT, Ip SP. Bioassay-Guided Isolation of Neuroprotective Compounds from Uncaria rhynchophylla against Beta-Amyloid-Induced Neurotoxicity. Evid Based Complement Alternat Med 2012; 2012802625.

[86] Feng Y, Wang XP, Yang SG, Wang YJ, Zhang X, Du XT, Sun XX, Zhao M, Huang L, Liu RT. Resveratrol inhibits beta-amyloid oligomeric cytotoxicity but does not prevent oligomer formation. Neurotoxicology 2009; 30 986-995.

[87] Murata N, Murakami K, Ozawa Y, Kinoshita N, Irie K, Shirasawa T, Shimizu T. Silymarin attenuated the amyloid $\beta$ plaque burden and improved behavioral abnormalities in an Alzheimer's disease mouse model. Biosci Biotechnol Biochem 2010; 74 2299-2306.

[88] Toda T, Sunagawa T, Kanda T, Tagashira M, Shirasawa T, Shimizu T. Apple Procyanidins Suppress Amyloid ß-protein aggregation. Biochem Res Int 2011; 2011784698.

[89] Roberts BE, Shorter J. Escaping amyloid fate. Nat Struct Mol Biol 2008; 15 544-546.

[90] Mereles D, Hunstein W. Epigallocatechin-3-gallate (EGCG) for clinical trials: more pitfalls than promises? Int J Mol Sci 12 5592-5603.

[91] Kuriyama S, Hozawa A, Ohmori K, Shimazu T, Matsui T, Ebihara S, Awata S, Nagatomi R, Arai H, Tsuji I. Green tea consumption and cognitive function: a cross-sectional study from the Tsurugaya Project 1. Am J Clin Nutr 2006; 83 355-361.

[92] Tan EK, Tan C, Fook-Chong SM, Lum SY, Chai A, Chung H, Shen H, Zhao Y, Teoh ML, Yih Y, Pavanni R, Chandran VR, Wong MC. Dose-dependent protective effect of coffee, tea, and smoking in Parkinson's disease: a study in ethnic Chinese. J Neurol Sci 2003; 216 163-167.

[93] Scapagnini G, Caruso C, Calabrese V. Therapeutic potential of dietary polyphenols against brain ageing and neurodegenerative disorders. Adv Exp Med Biol 2010; 698 27-35.

[94] Begum AN, Jones MR, Lim GP, Morihara T, Kim P, Heath DD, Rock CL, Pruitt MA, Yang F, Hudspeth B, Hu S, Faull KF, Teter B, Cole GM, Frautschy SA. Curcumin structure-function, bioavailability, and efficacy in models of neuroinflammation and Alzheimer's disease. J Pharmacol Exp Ther 2008; 326 196-208.

[95] Dube A, Nicolazzo JA, Larson I. Chitosan nanoparticles enhance the plasma exposure of (-)-epigallocatechin gallate in mice through an enhancement in intestinal stability. Eur J Pharm Sci 2011; 44 422-426. 
[96] Werner EA, Deluca HF. Retinoic acid is detected at relatively high levels in the CNS of adult rats. Am J Physiol Endocrinol Metab 2002; 282 E672-678.

[97] Marques MA, Kulstad JJ, Savard CE, Green PS, Lee SP, Craft S, Watson GS, Cook DG. Peripheral amyloid- $\beta$ levels regulate amyloid- $\beta$ clearance from the central nervous system. J Alzheimers Dis 2009; 16 325-329.

[98] Boada M, Ortiz P, Anaya F, Hernandez I, Munoz J, Nunez L, Olazaran J, Roca I, Cuberas G, Tarraga L, Buendia M, Pla RP, Ferrer I, Paez A. Amyloid-targeted therapeutics in Alzheimer's disease: use of human albumin in plasma exchange as a novel approach for A $\beta$ mobilization. Drug News Perspect 2009; 22 325-339.

[99] Kato M, Kawaguchi K, Nakai S, Murakami K, Hori H, Ohashi A, Hiki Y, Ito S, Shimano Y, Suzuki N, Sugiyama S, Ogawa H, Kusimoto H, Mutoh T, Yuzawa Y, Kitaguchi N. Potential therapeutic system for Alzheimer's disease: removal of blood A $\beta$ s by hemodialzyers and its effect on the cognitive functions of renal-failure patients. J Neural Transm 2012; .

[100] Sutcliffe JG, Hedlund PB, Thomas EA, Bloom FE, Hilbush BS. Peripheral reduction of $\beta$-amyloid is sufficient to reduce brain $\beta$-amyloid: implications for Alzheimer's disease. J Neurosci Res 2011; 89 808-814.

[101] Bell RD, Zlokovic BV. Neurovascular mechanisms and blood-brain barrier disorder in Alzheimer's disease. Acta Neuropathol 2009; 118 103-113.

[102] O'Dor R, Miloslavich P, Yarincik K. Marine biodiversity and biogeography--regional comparisons of global issues, an introduction. PLoS One 2010; 5 e11871.

[103] Gulf of Maine Biodiversity (http://www.coml.org/discoveries/ecology/ gulf_of_maine_biodiversity).

[104] Yooseph S, Sutton G, Rusch DB, Halpern AL, Williamson SJ, Remington K, Eisen JA, Heidelberg KB, Manning G, Li W, Jaroszewski L, Cieplak P, Miller CS, Li H, Mashiyama ST, Joachimiak MP, van Belle C, Chandonia JM, Soergel DA, Zhai Y, Natarajan K, Lee S, Raphael BJ, Bafna V, Friedman R, Brenner SE, Godzik A, Eisenberg D, Dixon JE, Taylor SS, Strausberg RL, Frazier M, Venter JC. The Sorcerer II Global Ocean Sampling expedition: expanding the universe of protein families. PLoS Biol 2007; 5 e16.

[105] Montaser R, Luesch H. Marine natural products: a new wave of drugs? Future Med Chem 2011; 3 1475-1489.

[106] Gerwick WH, Moore BS. Lessons from the past and charting the future of marine natural products drug discovery and chemical biology. Chem Biol 2012; 19 85-98.

[107] Blunt JW, Copp BR, Keyzers RA, Munro MH, Prinsep MR. Marine natural products. Nat Prod Rep 2012; 29 144-222. 
[108] Williams P, Sorribas A, Liang Z. New methods to explore marine resources for Alzheimer's therapeutics. Curr Alzheimer Res 2010; 7 210-213.

[109] Todgham AE, Hoaglund EA, Hofmann GE. Is cold the new hot? Elevated ubiquitinconjugated protein levels in tissues of Antarctic fish as evidence for cold-denaturation of proteins in vivo. J Comp Physiol B 2007; 177 857-866.

[110] Chen Z, Cheng CH, Zhang J, Cao L, Chen L, Zhou L, Jin Y, Ye H, Deng C, Dai Z, Xu Q, Hu P, Sun S, Shen Y, Chen L. Transcriptomic and genomic evolution under constant cold in Antarctic notothenioid fish. Proc Natl Acad Sci U S A 2008; 105 12944-12949.

[111] Gong Z, Croft K, Driedzic WR, Ewart KV. Chemical chaperoning action of glycerol on the antifreeze protein of rainbow smelt. J Therm Biol 2010; 36 78-83.

[112] Lordan S, Ross RP, Stanton C. Marine bioactives as functional food ingredients: potential to reduce the incidence of chronic diseases. Mar Drugs 2011; 9 1056-1100.

[113] Kang IJ, Jeon YE, Yin XF, Nam JS, You SG, Hong MS, Jang BG, Kim MJ. Butanol extract of Ecklonia cava prevents production and aggregation of beta-amyloid, and reduces beta-amyloid mediated neuronal death. Food Chem Toxicol 2011; 49 2252-2259.

[114] Jung WK, Ahn YW, Lee SH, Choi YH, Kim SK, Yea SS, Choi I, Park SG, Seo SK, Lee SW, Choi IW. Ecklonia cava ethanolic extracts inhibit lipopolysaccharide-induced cyclooxygenase-2 and inducible nitric oxide synthase expression in BV2 microglia via the MAP kinase and NF-kappaB pathways. Food Chem Toxicol 2009; 47 410-417.

[115] Wijesekara I, Yoon NY, Kim SK. Phlorotannins from Ecklonia cava (Phaeophyceae): biological activities and potential health benefits. Biofactors 2010; 36 408-414.

[116] Wijesinghe WA, Jeon YJ. Enzyme-assistant extraction (EAE) of bioactive components: a useful approach for recovery of industrially important metabolites from seaweeds: a review. Fitoterapia 2012; 83 6-12.

[117] Alonso E, Vale C, Vieytes MR, Laferla FM, Gimenez-Llort L, Botana LM. 13-Desmethyl spirolide- $C$ is neuroprotective and reduces intracellular $A \beta$ and hyperphosphorylated tau in vitro. Neurochem Int 2011; 59 1056-1065.

[118] Papp E, Csermely P. Chemical chaperones: mechanisms of action and potential use. Handb Exp Pharmacol 2006; 405-416.

[119] Yancey PH. Organic osmolytes as compatible, metabolic and counteracting cytoprotectants in high osmolarity and other stresses. J Exp Biol 2005; 208 2819-2830.

[120] Yang DS, Yip CM, Huang TH, Chakrabartty A, Fraser PE. Manipulating the amyloid$\beta$ aggregation pathway with chemical chaperones. J Biol Chem 1999; 274 32970-32974. 
[121] Uversky VN, Li J, Fink AL. Trimethylamine-N-oxide-induced folding of $\alpha$-synuclein. FEBS Lett 2001; 509 31-35.

[122] Benkendorff K. Aquaculture and the production of pharmaceuticals and nutraceuticals. In: Burnell G, G. A (Eds.), New technologies in aquaculture: improving production efficiency, quality and environmental management, Woodhead Publishing, Cambridge, U.K., 2009, pp. 866-892.

[123] Faulkner DJ. Marine pharmacology. Antonie Van Leeuwenhoek 2000; 77 135-145.

[124] Hafting JT, Critchley AT, Cornish ML, Hubley SA, Archibald AF. On-land cultivation of functional seaweed products for human usage. J Appl Phycol 2012; 24 385-392.

[125] Subhadra B. Algal biorefinery-based industry: an approach to address fuel and food insecurity for a carbon-smart world. J Sci Food Agric 2010; 91 2-13.

[126] Stewart G, Noyes-Hull G, Feasibility of producing value added products from snow crab processing waste in Cape Breton, Nova Scotia, Gulf Aquarium and Marine Station Cooperative, Cheticamp, Canada, 2010; 44 p.

[127] Reid GK, Robinson SMC, Chopin T, Mullen J, Lander T, Sawhney M, MacDonald B, Haya K, Burridge L, Page F, Ridler N, Boyne-Travis S, Sewuster J, Marvin R, Szemerda M, Powell F. Recent developments and challenges for open-water, integrated multi-trophic aquaculture (IMTA) in the Bay of Fundy, Canada. AAC Special Publication 2011; 13 43-47.

[128] Chopin T, Neori A, Buschmann A, Pang S, Sawhney M. Diversification of the aquaculture sector: seaweed cultivation, integrated multi-trophic aquaculture,integrated sequential biorefineries. Global Aquaculture Advocate 2011; 14 58-60.

[129] Ono K, Takahashi R, Ikeda T, Yamada M. Cross-seeding effects of amyloid $\beta$-protein and $\alpha$-synuclein. J Neurochem 2012; e-publication in press (doi: 10.1111/j. 1471-4159.2012.07847.x) 